\title{
Insecticidal Property of Jackfruit (Artocarpus heterophyllus) Peel Ethanol Extract against Rice Weevils (Sitophilus oryzae)
}

\author{
Liwayway H. Acero* \\ Department of Natural Sciences, College of Arts and Sciences, San Beda University Manila Philippines. \\ * Corresponding author. Email: lilyacero1@yahoo.com \\ Manuscript submitted October 8, 2018; accepted February 12, 2019. \\ doi: 10.17706/ijbbb.2019.9.3.158-165
}

\begin{abstract}
Insects are known as pests at home which can lower the quality of food for human. There are insects that destroy the quality of farm harvest, thereby decreasing its palatability and marketability. One of the very well- known insects pests is the rice weevils (Sitophilus oryzae) which damages the quality of rice grain and lowers its market value. This study seeks to find out what concentration of Jackfruit Peel Ethanol Extract (JPEE) will give the highest mortality in 1.2 hours of observation. Experimental research method with four treatments, and twenty (rice weevils) samples/treatment, was used to gather pertinent data on this study. Jackfruit Peel was oven dried, grounded, macerated in $70 \%$ ethanol for 3 days and subjected to rotary evaporation. Different concentrations of Jackfruit Peel ethanol extract, (JPEE) was done. T- (control), 0\% JPEE, $\mathrm{T}_{1}, 25 \%$ JPEE, $\mathrm{T}_{2}, 50 \%$ JPEE and $\mathrm{T}_{3}, 75 \%$ JPEE. Data on mortality for 1.2 hours with 20 minutes interval, was analyzed using Analysis of Variance and Fisher Least Significant Difference (LSD) Test as post hoc Test. Result revealed significant difference on the means of four treatments. It is imperative that rice weevils in $\mathrm{T}_{3}$ (750\% of Jackfruit Peel Ethanol Extract) gave highest mortality in 1.2 hours, when exposed to JPEE. ANOVA revealed significant difference at 5\% level of significance. Fisher LSD showed significant difference on control and treatments with JPEE. No significant differences exist among treatment with JPEE, which implies that any of the three treatment with JPEE can control rice weevils at 1.2 hours of observation. It shows that JPEE is a potential source of insecticide particularly for rice weevils.
\end{abstract}

Key words: Jackfruit peel, rice weevils, (Sitophilus oryzae).

\section{Introduction}

Rice is the main energy source for Filipinos. Most farmers grow rice in their farm to supply the staple food for the entire populace. Philippines being tropical, favor the existence of insect pests not only in their farm but even on their post-harvest facilities like rice granary. In the early weeks of September 2018, about 132,400 bags of rice from Thailand and Vietnam that were unloaded in Subic port Philippines were found infested with weevils or "bukbok." The heat inside the ship became conducive to the hatching of weevil eggs [1]. Indigenous plant base environment friendly insecticide are now gaining popular than commercial insecticide. Insect pest like weevil destroys rice grains in storage areas causing decrease in quality and palatability. The rice weevil, (Sitophilus oryzae) belongs to order Coleptera and family Curculionide. Adult is small ( 2.5 to $4 \mathrm{~mm}$ ), dark brown. It has chewing mouthparts at the end of their snouts or prolonged heads, and is about 1/8- to 3/16-inch long, depending on the size of the grain kernel. The adult rice weevil is a dull 
reddish-brown with round or irregularly shaped pits on the thorax and four light spots on the wing covers. Adult rice weevils live for four to five months and each female lays 300 to 400 eggs during this period. The female uses her strong mandibles to chew a hole in the grain kernel where she deposits a single egg and seals the hole with a gelatinous fluid. Damage to grain caused by this weevil includes reductions in nutritional value, germination, weight and commercial value [2]. The use of insecticide from herbal plants in lieu of synthetic insecticide is becoming popular in the market. It will not harm the environment and will maximize the use of herbal plants in the locality.

Jackfruit is a tropical fruit that is very popular among Filipinos. Its flesh or fruit pods, are edible both when ripe and unripe. When unripe, Filipinos cook it with coconut milk and dried fish or shrimp, as one of vegetable in their viand. The aromatic fruit when ripe can be eaten as raw or as one of the ingredients in many Filipino delicacies. However the peel are just thrown away after the removal of the fruit pod. Ethanolic and methanolic extracts of Jackfruit peels contain phytochemicals as revealed in the phytochemical screening. The presence of alkaloids, flavonoids, carbohydrates, proteins and triterpenoids are the active compounds in the screening done. The Gas Chromatography-Mass Spectroscopic analysis of various extracts like ethanol and methanol identified the presence of various phytochemical compounds and secondary metabolites like Hexadecanoic acid, Squalene, Calophyllolide, Thialisopyine and so on. Nuclear Mass Resonance Spectroscopy showed the presence of Alkyl group and carbon bearing OH group compounds. Atomic Absorption Spectroscopy of peel indicated the presence of major minerals like calcium, potassium and other minor minerals. All these findings implied the availability of various active and phytochemical compounds and also some minerals from the peel [3]. The peel extract exhibited the highest total phenolic and total flavonoid content, and the phenolics was 4.65, 4.12 and 4.95 times higher than that of pulp, flake and seed extract, respectively. The strongest DPPH and ABTS + scavenging ability, $\alpha$-glucosidase inhibition were also found in peel extract, and the $\alpha$-glucosidase inhibition was about 11.8-fold of that of acarbose. The HPLC-QTOF-MS/MS analysis led to the tentative identification of 53 compounds, prenylflavonoids, hydroxycinnamic acids and glycosides are the predominant bioactive compounds [4]. The pulp of ripe fruit, contains doubled amouount of gallic acid $(19.31 \mu \mathrm{g} / \mathrm{g})$ than the unripe peel, while ferulic acid $(2.66 \mu \mathrm{g} / \mathrm{g})$ was drastically reduced. Tannic acid $(5.24 \mu \mathrm{g} / \mathrm{g})$ increased as compared to raw pulp of fruit skin [5]. Tannins are bitter-tasting phenolic compounds found in flowering woody plants like jackfruit and use it as defense against its predators.

No published study on the use of jackfruit peel, as insecticide, hence this study. This study was conducted mainly to investigate the insecticidal potential of Jackfruit peel against rice weevil. The result of this study is beneficial, to partner communities of San Beda University-Institutional Community Engagement Center, where rice farming and selling is the main source of livelihood. Specifically this study answers the following research questions:

1) What is the mortality of rice weevils in different concentrations of Jackfruit Peel seeds Ethanol extract (JPEE) every 20 minutes observation, for 1.2 hours?

2) What is the behaviour of rice weevils in different concentration of Jackfruit Peel Ethanol extract (JPEE) every 20 minutes observation?

3) Is there a significant difference on the mortality of rice weevils in different concentrations of Jackfruit Peel Ethanol extract (JPEE) every 20 minutes of observation.

\section{Methodology}

\subsection{Preparation of Jackfruit Peel Ethanol Extract (JPEE)}

The method of JPEE preparation was patterned from several studies with slight modification. Peel of ripe 
Jackfruit were oven dried at $100{ }^{\circ} \mathrm{C}$ [6] (Fig. 1a). When the peel is already crispy it was grounded in a mechanical grinder [7] (Fig. 1b). Ground jackfruit peel was macerated to solvent (70\% Ethanol), following the ratio of $1: 4 \mathrm{w} / \mathrm{v}$ [8]. Maceration was done for 3 days with constant agitation (Fig. 2). The mixture was filtered with the use of cheese cloth and Whatman paper no. 1, and was subjected to rotary evaporation to remove the ethanol (Fig. 3).

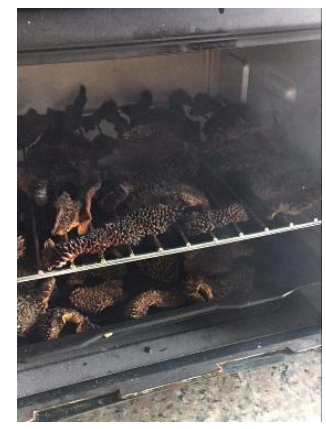

Fig. 1 a. Jackfuit peel in the oven.

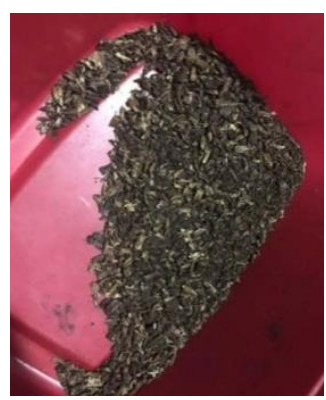

Fig. 1 b. Grounded jackfruit peel.

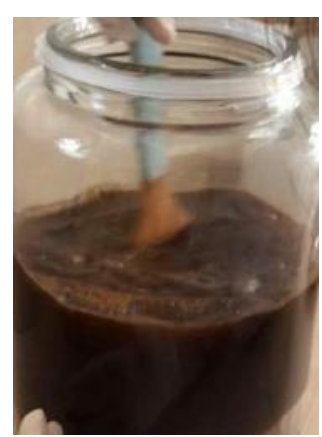

Fig. 2. Maceration of JPEE.

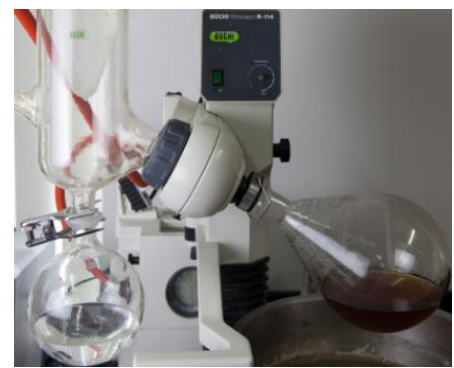

Fig. 3. JPEE in rotary evaporator.

\subsection{Application of JPEE/Exposure Technique}

Force-feeding tests was conducted following the procedures adopted by several insecticidal studies using herbal extracts with slight modifications, [9]-[14]. Four pairs of sterilized petri dishes (dia. $5.5 \mathrm{~cm}$ ) were used. JPEE was diluted in distilled water, in different concentrations as follows; T1, 25\% JPEE, T2, 50\% JPEE, and T3, 75\% JPEE (Fig. 4). Each filter paper in the bottom of petri dish was fully absorbed with JPEE (Fig. 5).

Infusion was carried out using a syringe. For each concentration a new syringe was used. Distilled water was used for control (T-). Twenty live rice weevils were subsequently introduced in each petri dish, after which the insects were touched at the abdomen using glass rod to determine its mobility. Each treatment has 20 rice weevils. Data for the mortality of the rice weevils was recorded every 20 minutes for one hour and 20 minutes [15]. 


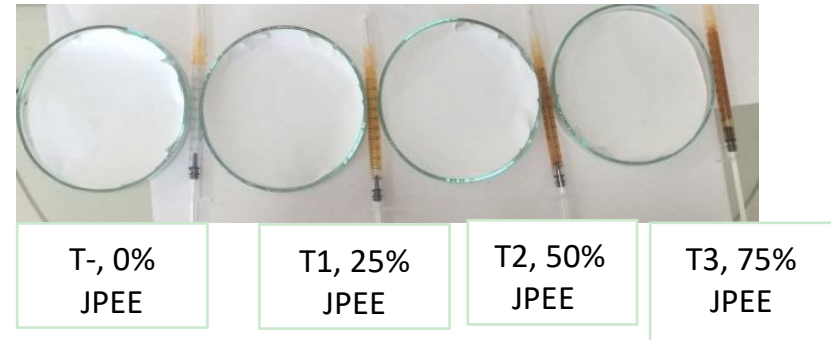

Fig. 4. JPEE in different concentrations.

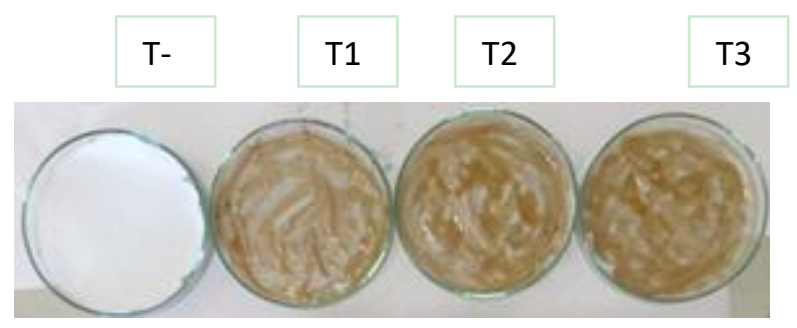

Fig. 5. JPEE in Petri dishes.

\subsection{Data Analysis}

Data on mortality was analyzed using Analysis of Variance (ANOVA) and Fisher Least Significant Difference Test as post hoc test.

\section{Results and Discussion}

\subsection{Number of Rice Weevils, per Treatment on the Start of the Study}

Number of live rice weevils per treatment is shown in Table 1. To ensure uniformity and avoid bias in the result on the controlled variables, twenty live rice weevils were obtained from the same sack of rice from the stockroom of a rice trader in Palanan, Makati City Philippines. It was collected from an infested sack of rice in the "bodega" which was characterized by off odour and low quality of rice.

Table 1. Number of Rice Weevils per Treatment on the Start of the Study

\begin{tabular}{lllll}
\hline \hline Treatment & - & 1 & 2 & 3 \\
\hline $\begin{array}{l}\text { Number of rice } \\
\text { weevils }\end{array}$ & 20 & 20 & 20 & 20 \\
\hline Mean & 20 & 20 & 20 & 20 \\
\hline
\end{tabular}

\subsection{Mortality of Rice Weevils per Treatment for 1.5 Hours Observation}

Mortality in this study is described as non-motility of rice weevils even if touch by glass rod on their abdominal part. Table 2 posited the mortality per treatment every 20 minutes of observation. Highest mortality was observed in treatment $3,100 \%$ mortality, followed by $\mathrm{T}_{2}, 80 \%$ mortality and $\mathrm{T}_{1}$, with $75 \%$ mortality. No mortality was observed in T- (control). Result revealed that increasing the percentage of SSEE also increases mortality. Fig. 6 displays the percentage of mortality per treatment in graph, which denotes that $\mathrm{T}_{3}$ had the highest mortality even in 1.2 hours of observation. Table 2 revealed highest percentage of mortality in $\mathrm{T}_{3}, 75 \%$ JPEE) at 1.2 hours observation. Table 3 (ANOVA) revealed significant differences among the four treatments. Significant differences exist between pairs of means with different superscripts as revealed by Fisher LSD (T- vs T1, T2 and T3). The result further implies that 25\% to $75 \%$ of JPEE caused death/mortality of the rice weevils in 1.2 hours.. The mortality of the rice weevils may have resulted from 
the biocidal effects of the plants which contains active components [16].

Several studies can attest to the claims of this study. Crude plant extracts causes toxicity [17]. and feeding inhibition of insects [18]. Jackfruit has a multifaceted properties like antiasthmatic, antioxidant, antibacterial, antifungal, anticancer, hypoglycemic, antimalaral, antidiarrheal, antiarthritic, anthelmintic, anti-inflammatory, antiplatelets, antiviral, and show wound healing effect [19]. The presence of flavonoids in jackfruit peel is one the possible causes of its mortality. The effects of higher doses of flavonoids in insects alter normal body functions. The presence of these phytochemical alters some biochemical functions of organisms. The effects of flavonoids on the transhydrogenation, NADH oxidase, and succinate dehydrogenase reactions suggest that compounds of this nature may prove valuable in the control of insect populations by affecting mitochondrial enzyme components [20].

Table 2. Mortality per Treatment Every Fifteen Minutes of Observation

\begin{tabular}{|c|c|c|c|c|}
\hline Treatment & - & I & 2 & 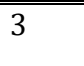 \\
\hline First 20 minutes & 0 & 2 & 3 & 4 \\
\hline Second 20 minutes & 0 & 5 & 9 & 12 \\
\hline Third 20 minutes & 0 & 4 & 3 & 4 \\
\hline Fourth 20 minutes & 0 & 3 & 2 & 2 \\
\hline Total & 0 & 14 & 17 & 20 \\
\hline Mean & $0^{\mathrm{a}}$ & $3.5^{\text {be }}$ & $4.25^{\mathrm{ce}}$ & $5.5^{\mathrm{de}}$ \\
\hline$\%$ of mortality & 0 & 70 & 85 & 100 \\
\hline
\end{tabular}

Table 3. Analysis of Variance (ANOVA)

\begin{tabular}{lcccccc}
\hline \multicolumn{1}{c}{ S.V. } & SS & $d f$ & MS & $F$ & P-value & F crit \\
\hline Rows & 56.18 & 3 & 18.72 & $4.37^{*}$ & 0.036 & 3.86 \\
Columns & 66.68 & 3 & 22.22 & $5.18^{*}$ & 0.023 & 3.86 \\
Error & 38.56 & 9 & 4.28 & & & \\
Total & 161.4375 & 15 & & & & \\
\hline \multicolumn{7}{l}{ Legend: } \\
\end{tabular}

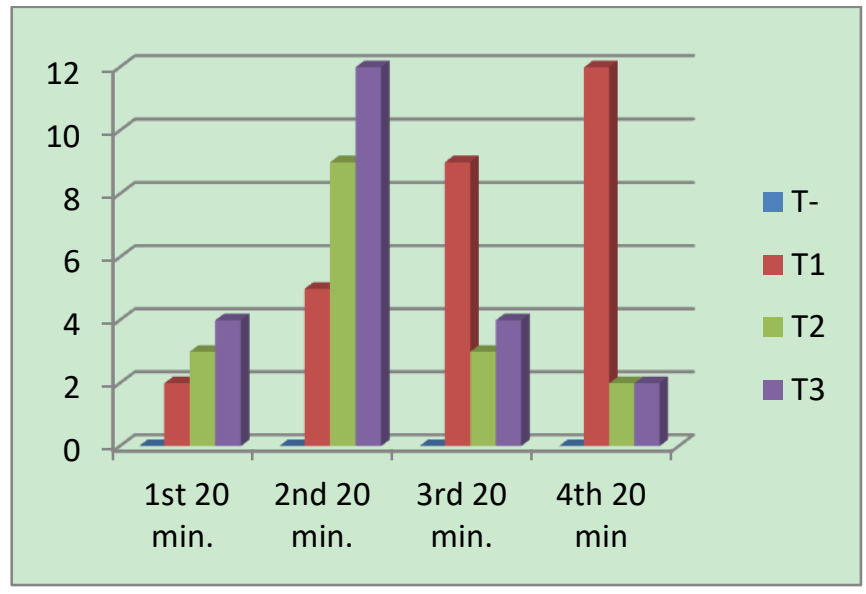

Fig. 6. Percentage of mortality per treatment.

\subsection{Behaviour of Rice Weevils every 15 Minutes of Observation}

Table 4 summarized the behaviour of rice weevils per treatment. On the first 20 minutes, experimental insects are lethargic /weak. Most of the insects stay on the sides of petri dish and evaded the JPEE area 
(Fig. 7). Insects will tend to evade areas with pungent odor and with tannin content [21]. On the $2^{\text {nd }} 20$ minutes, insects lie on their back and the legs are still moving. On the third $3^{\text {rd }} 20$ minutes, remaining insects were totally weak, paralyzed, but still moving if touch by glass rod in their abdomen. Rice weevils in negative control (T-) were all active.

It can be gleaned from Table 4 that rice weevils were affected by the biochemical components of JPEE. Tannin enters the epidermal tissues of insects and causes off-feeding of insects thereby affecting its body movements. The conspicuous/abrupt change in their locomotion is characterized by weakness as early as 20 minutes of exposure to JPEE. After 40 minutes of exposure, paralysis was observed in treatments with SSEE. Touching the abdominal regions of the rice weevils, with glass rod indicates that they are still alive, by movement of the legs even if the insects lie on their back. Paralysis of the entire body except the limbs is as indication that the physiologic functions were already disturbed. Tannin present in jackfruit peel is characterized by astringent, bitter plant polyphenols that either bind and precipitate or shrink proteins. The astringency from the tannins causes the dry and puckery feeling in the mouth following the consumption of red wine, strong tea, or an unripened fruit [22]. Tannins are astringent (mouth puckering) bitter polyphenols and act as feeding deterrents to many insect pests [23]. With the highest mortality in $\mathrm{T}_{3}$, it is imperative that jackfruit peel can be used as insecticide (rice weevil). Studies on the use of jackfruit peel in different concentrations shall be explored on other insect pests.

Table 4. Behavior of Rice Weevils for 1.2 Hours Observation

\begin{tabular}{lllll}
\hline \hline Treatment & - & \multicolumn{1}{c}{ I } & 2 & 3 \\
\hline First 20 minutes & active & weak & weak & weak \\
\hline Second 20 minutes & active & Lie on their back & Lie on their back & Lie on their back \\
\hline Third 20 minutes & active & paralyzed & paralyzed & paralyzed \\
\hline Fourth 20 minutes & active & paralyzed & paralyzed & paralyzed \\
\hline
\end{tabular}

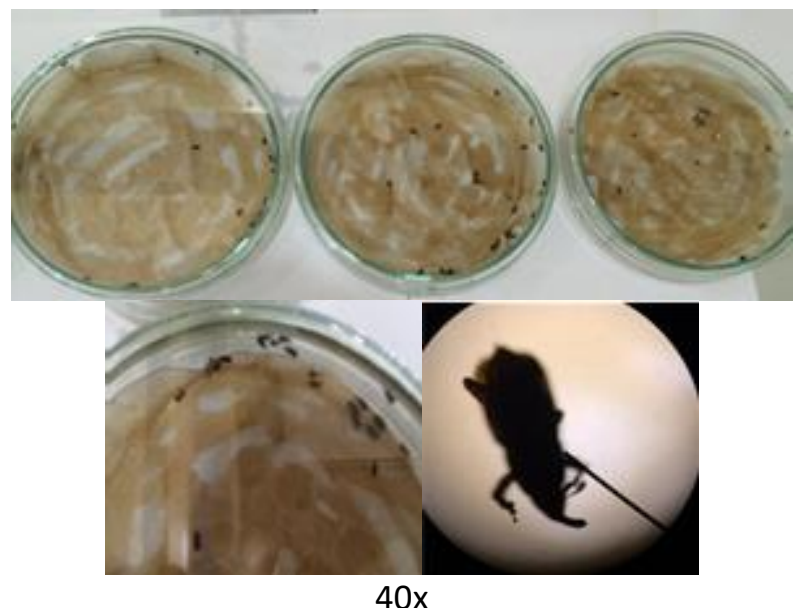

Fig. 7. Rice weevils moved to JPEE free area.

\section{Conclusion}

Insect Pests of rice like rice weevils needs to be treated with chemicals that are less potent to human. These chemicals need to be originated from plants. Jackfruit peels are just thrown away, after consumption of the fruit pod. This study revealed significant result when jackfruit peel was macerated in $70 \%$ ethanol and administered to rice weevils in different concentrations (25\%, 50\% and 75\%). The use of JPEE from $25 \%$ to $75 \%$ yielded mortality as early as 20 minutes observation, but it is more potent at 40 minutes exposure of rice weevils in JPEE. It is imperative that jackfruit peel can be used as insecticide (rice weevils). Studies on the use of JPEE in different concentrations shall be explored on other insect pests. 


\section{Acknowledgment}

The author would like to acknowledge, the San Beda University Administrators of the College of Arts and Sciences, San Beda College Manila; Dr. Christian Bryan Bustamante-Dean, Dr. Moses Aaron Angeles -Vice-Dean, for their encouragement.

\section{References}

[1] Ocampo, K. (2018). Imported rice now weevil-free; to augment NFA supply, Inquirer.Net.

[2] Rashid, M., \& Haque, M., et al. (2008). A study on resistance of different rice varieties against rice weevil, Sitophilus oryzae (L). International Journal on Sustainable Crop Production, 4(1), 35-40.

[3] Sundarraj, S., \& Ranganathan, T. (2017). Phytochemical screening and spectroscopy analysis of jackfruit (Artocarpus integer Thumb.) peel. International Research Journal of Pharmacy, 8(9), 151-157.

[4] Zhang, L., et al. (2017). Jackfruit (Artocarpus heterophyllus Lam.) peel: A better source of antioxidants and a-glucosidase inhibitors than pulp, flake and seed, and phytochemical profile by HPLC-QTOF-MS. Journal of Food Chemistry, 234(1), 303-313.

[5] Singh, A., et al. (2015). Studies on the phenolic acid contents in different parts of raw and ripe jackfruit and their importance in human health. International Journal of Applied Science-Research and Review, 2(3), 069-073.

[6] Chang, T., Chao, S., \& Ding, Y., (2012). Melanogenesis inhibition by homoiso flavavone sappanone A from Caesalpinia sappan. International Journal of Molecular Science, 13(8), 10359-10367

[7] Bourmita, Y., et al. (2013). Anti-termitic activity of aqueous extracts from saharan toxic plants against Anacanthotermes ochraceus. Journal of Entomology, 10(1), 207-213.

[8] Morte, Y., \& Acero, L. (2017). Potential of calamansi (Citrofortunella microcarpa) fruit peels extract in lowering the blood glucose level of streptozotocin induced albino rats (Rattus albus). International Journal of Food Engineering, 3(1), 29-34.

[9] Ahmad, I., \& Suliyat, T. (2011). Development of fipronil gel bait against german cockroaches, Blattella ermanica Dictyoptera: Blattellidae): Laboratory and field performance in Bandung, Indonesia. Journal of Entomology, 8(3), 288-294.

[10] Smith, V. (1979). Improved techniques designed for screening candidate termiticides on soil in the laboratory. Journal of Economical Entomology, 72(1), 877-879.

[11] Sattar, A., Naeem, M., \& Ehsan-ul-Haq. (2014). Efficacy of plant extracts against subterranean termites i.e., Microtermes obesi and Odontotermes lokandi (Blattodea:Termitidae). Journal of Biodiversity Bioprospecting Development, 1(1), 1:122.

[12] Gedam, P., \& Sampathkumaran, P. (1986). Cashew nut shell liquid: extraction, chemistry and applications. Progress in Organic Coatings, 14(1), 15-157

[13] Edori, O., \& Ekpete, O. (2015). Phytochemical screening of aqueous extract of Icacina trichantha roots and its effect on mortality of wood termites. World Journal of Pharmaceutical Research, 4(10), 213-224.

[14] Abbas, M., et al. (2013). Antitermitic activity and phytochemical analysis of fifteen medicinal plant seeds. Journal of Medicinal Plant Research, 22(1),1608-1617.

[15] Aihetasham, A., et al. (2015). Bioactivity of medicinal plants Mentha arvensis and Peganum harmala extracts against Heterotermes indicola (Wasmann) (Isoptera). International Journal of Bioscience, 7(5), 116-126

[16] Al-Saady, T. (2001). The effect of some plants extracts on the survival and production of adult of Callosobrachus maculates (Forbicius) (Coleoptera: Bruchidae). Master of science degree thesis, Agriculture College, Basrah University.

[17] Hiremath, I. G., \& Ahn, Y. J. (1997). Parthenium as a source of pesticide. Proceedings of First 
International Conference on Parthenium management.

[18] Wheeler, D., \& Isman, M. (2001). Antifeedant and toxic activity off Trichilia americana extract against the larvae of Spodoptera litura. Entomologia Experimentalis et Applicata, 98(1), 9-16.

[19] Tejpal, A., \& Amrita, P. (2016). Jackfruit: A health boom. International Journal of Research Ayurveda Pharmacology, 7(3), 59-64.

[20] Catherine, C., Jude, I., \& Ngozi, I. (2009). Profile of Chromolaena odorata. International Journal of Scientific and Research Publication, 3(1), 524.

[21] Acero, L. H. (2017). Fresh siam weed (Chromolaena odorota) leaf extract in the control of housefly (Musca domestica). International Journal of Food Engineering, 3(1), 56-60.

[22] McGee, H. (2004). On Food and Cooking. Simon \& Schuster, New York.

[23] War, A., et al. (2012). Mechanisms of plant defense against insect herbivores. Plant Signalling and Behavior, 7(10), 1306-1320.

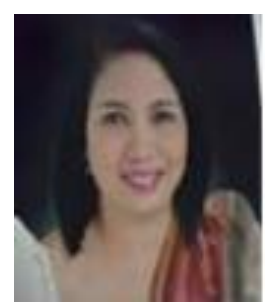

Liwayway H. Acero is a member of Asia Pacific Chemistry, Biology, Environment, Engineering Society, editorial member for Global Science and Technology Forum and Palawan Scientist. She is one of the Technical panels of the International Journal of Food Engineering and Technology. Educational background: DST Biology in 2009 from the University of the Philippines-Open University in Los Banos Laguna. Doctor of Education major in Educational Management from Palawan State University on March 2003. She conducted her dissertation at Okayama University Graduate School Education in Japan on March to June 2000 as research fellow. She received her Master of Science degree in agricultural education-Plant Science (Agronomy) from the Western Philippines University in Aborlan, Palawan, Philippines on April 1993. She got her Bachelor of Science degree in Agriculture (cum laude), major in Animal science and minor in Plant Science (agronomy) from the Western Philippines University in Aborlan, Palawan Philippines on April 1986. She is a professor and the chairperson of the Department of Natural Sciences, College of Arts \& Science in San Beda University, Mendiola, Manila, Philippines. Prior to her employment in San Beda University in Manila, she had served as professor for 20 years in Western Philippines University in Puerto Princesa City Palawan, Philippines. She handled several administrative works aside from teaching profession. She served as assistant dean of Western Philippines University, Puerto-Princesa Campus, Director for Instruction, Department Chairperson of the Education, Department chairperson of the Agribusiness Department \& chairperson for the thesis committee. She had 21 publications. Eighteen of her publications are international publications and can be found in the online data-base system and are indexed by google scholar. 